\title{
Research on the Rheological Properties of Asphalt Binder Modified by Fume Silica and Crumb Rubber Compound
}

\author{
Mustafa Akpolat ${ }^{1 *}$, Baha Vural Kök², Ercan Aydoğmuş3 \\ 1 Department of Civil Engineering, Faculty of Engineering, Munzur University, 62000, Tunceli, Turkey \\ 2 Department of Civil Engineering, Faculty of Engineering, Firat University, 23119, Elazı $\breve{g}$, Turkey \\ ${ }^{3}$ Department of Chemical Engineering, Faculty of Engineering, Firat University, 23119, Elazığ, Turkey \\ * Corresponding author, e-mail: mustafaakpolat@munzur.edu.tr
}

Received: 23 August 2021, Accepted: 08 February 2022, Published online: 16 February 2022

\begin{abstract}
This study investigates the effect of using Fume Silica (Aerosol 300) alone and together with crumb rubber (CR) in bitumen modification on the traditional and rheological properties of the binder and compares it to the SBS modified binder. Using the aerosol additive in the binder at the rates of $0.5 \%, 1 \%, 1.5 \%$, and $2 \%$ were determined as the most convenient ratio and CR+aerosol modified binders were prepared per this ratio. The binders were subjected to the softening point, viscosity, frequency sweep, bending beam rheometer (BBR), and Fourier Transform Infrared spectroscopy (FTIR) tests in the context of the study. Besides, the optimum conditions were determined according to the response functions by designing an experiment with statistical regression according to the Response surface methodology (RSM). The results indicate that the optimum aerosol ratio is $1.5 \%$. With the use of $1.5 \%$ aerosol in $6 \%$ CR modification per bitumen weight, it was found that (1) the softening point increases and the temperature sensitivity decrease in comparison to other binders, (2) the consistency of the binder increases, (3) the complex modulus values increase and become more resistant to rutting, (4) the low-temperature parameters enhance by performing more flexible behavior, (5) there may be physical changes in the structure even though there is no chemical reaction in the binder with the use of CR and aerosol additives, and (6) the experimental data and theoretical data obtained from the RSM method are consistent as per the statistical analysis.
\end{abstract}

Keywords

fume silica, crumb rubber, modification, rheology, response surface methodology

\section{Introduction}

With the developing technology, scientists have conducted numerous studies to provide more durable and stable roads. The harsh conditions of nature and climatic events requires the strengthening of the physical and chemical structure of asphalt roads. Various additives are used for the modified bitumen to yield maximum performance under low and high-temperature conditions.

The polymers used in bitumen are generally categorized as thermoplastic elastomers and plastomers [1]. As an alternative to polymers, the crumb rubber (CR) additive was stated to have a positive effect on the performance of binders and be more environmentally friendly and cost-effective [2-4]. It is expressed that styrene-butadiene-sytrene (SBS) and CR as polymer additives improve the high (rutting) and low-temperature (cracking resistance) parameters of the binder $[5,6]$, raising the mixing-compaction temperatures by increasing the viscosity $[7,8]$, and also decrease the temperature sensitivity by increasing the softening point values [9].

In addition to various polymers and $\mathrm{CR}$, nanocomposite materials have started to be frequently used in bitumen modifications in recent years, just as in many different areas. In the study, it was stated that nanomaterials could potentially increase the high temperature sensitivity resistance, storage stability and rheological properties of asphalt binder samples [10].

Cheraghian et al. [11] investigated the aging process of bitumen modified by clay and fumigated silica nanoparticles. The volume fraction of silica nanoparticles in bitumen was studied in the range of $1 \%-3 \%$ and the temperature between 30 and $70{ }^{\circ} \mathrm{C}$. When clay and fumed silica nanoparticles were used in bitumen modification, the carbonyl index and degree of oxidation decreased. Besides, it was observed that the aging resistance and mechanical 
stability of bitumen to ultraviolet radiation increased. When fumed silica nanoparticles were mixed into bitumen in different proportions $(0.1,0.2$, and $0.3 \%)$ by weight, the oxidation degree and carbonyl index were found to have improved according to the results of ultraviolet aging [12].

Polyurethane-based modified binder was obtained by the chemical reaction of MDI (4,4'-diphenylmethane diisocyanate) with polyethylene glycol and nanosilica. The nanosilica content was kept at $0.08 \%$ by mass compared to the bitumen, the other mixing ratios were changed, and the performance of the modified bitumen was evaluated. When nanosilica and polyethylene glycol were pre-mixed with MDI and then added to bitumen, it was observed that the rutting resistance and thermal stability were improved [13].

Taherkhani and Afroozi [14] investigated the creep behavior of asphalt mixture containing nano-silica. As a result, they stated that the flow number increased, and the steady-state strain rate decreased with escalating nanosilica content. They argued that this would increase the resistance against permanent deformation.

Zghair et al. [15] examined the rheological properties of $2 \%, 4 \%$, and $6 \%$ nano silica modified binders and expressed that the stiffness of the binder increased, and temperature sensitivity decreased with the escalating percentage of nano silica.

It was determined that hybrid organic-inorganic bitumen powders obtained from nanosilica and bitumen core homogeneously covered the aggregates in the mixture and improved the binding properties of bitumen. According to the results obtained in hybrid mixtures, an industrial product was developed that provided multiple advantages such as storage, transportation, and ease of applicability [16].

The use of recycling, waste, or byproducts with bitumen binders to extend the service life of asphalt pavement has become widespread. Addition of reed fly ash to the asphalt binder was observed to have a positive effect on the performance of the mixture. As the rate of reed fly ash increased, the bulk density decreased while the volumetric void, porosity and permeability increased. In addition, at low mixing ratios $(6 \%)$, the resistance to abrasion increased by $36 \%$ [17].

Motamedi et al. [18] examined the fatigue life of asphalt binders, mastics, and asphalt mixtures modified with nano-silica and synthesized polyurethane. They stated that the fatigue life of the mastic and asphalt mixture increased with nano-silica and synthesized polyurethane additives.

$0.3 \%$ nano-silica (SiO2NP) modified binders and mixtures were stated to improve rutting resistance, fatigue parameter, and moisture damage resistance in comparison to the neat binders and mixtures. Besides, scanning electron microscopy (SEM) results unfold that homogeneous binders can be obtained with nano-silica [19].

Rezaei et al. [20, 21] stated that the addition of nano silica to SBS modified binders can improve rutting resistance. In addition, they suggested that the mixtures prepared with SBS/nano silica modified binder revealed high flow numbers, indicating that their performance at high temperatures improved.

Sadiq Bhat and Shafi Mir [22] suggested that the addition of nano $\mathrm{Al}_{2} \mathrm{O}_{3}$ had a positive effect on the rutting and fatigue performance of SBS modified asphalt binders, the storage stability of SBS modified asphalt binders significantly advanced after the addition of nano $\mathrm{Al}_{2} \mathrm{O}_{3}$, and their aging resistance also improved.

Han et al. [23] detected that the use of nano-silica and CR together as asphalt additives improved the rutting resistance and low-temperature performance.

It was determined that the viscosity of bitumen modified with new crumb rubber increased, and its rheological properties improved at high temperature as well as exhibiting different viscoelastic behavior than styrene-butadiene-styrene (SBS) block copolymer.

The improvement of high-temperature rheological properties of bitumen binders depends on both $\mathrm{CR}$ and bitumen sources. The results of ANOVA revealed that the effect of high-temperature bitumen sources on modified products has greater contribution as compared to the CR percentages by mass [24].

Chen et al. [25] investigated the rheological characterization of SBS modified bitumen using the time-temperature superposition principle (TTSP), and the results were evaluated with horizontal displacement of isothermal curves. This method has been validated to determine the relationship of bitumen source, modified type and aging with TTSP in SBS modified bitumen. TTSP method yielded appropriate results in samples prepared with different bitumen sources and modified species. However, this method was determined to have yielded inconsistent results in SBS modified bitumen samples that were aged too short or too long.

Wang et al. [26] investigated the thermal and UV aging stages of different types of bitumen modified by 5 wt.\% nanoclay and SBS binders. The modified bitumen was aged according to the Rolling Thin Film Oven Test (RTFOT) and UV-Aging methods. The obtained results revealed that UV-aging mechanism showed different 
results than thermal-oxidative aging. The addition of processed nanoclay materials improved the resistance of bitumen to ultraviolet aging.

Nanoclay has been preferred in bitumen modification due to its low cost and abundance in nature. The physical and chemical properties of bitumen containing different proportions $(3 \%, 5 \%, 7 \%$ and $9 \%)$ of nanokaolin clay by mass were investigated. It was determined that nanoclay positively affected the softening point and storage stability of modified bitumen [27].

\section{Materials and experimental methods}

\subsection{Materials}

This study examines the traditional and rheological properties of the modified binders using the additive ratios shown in Fig. 1. Crum rubber (separated with sieve No. 40), SBS, and Fumed Silica (Aerosil 300) were used as additives. Table 1 explains the properties of the additives used in the study. Aerosil scanning electron microscope (SEM) images were given in Fig. 2.

Modified binders were prepared with bitumen having a penetration grade of B160/220 obtained from Batman TÜPRAŞ refinery.
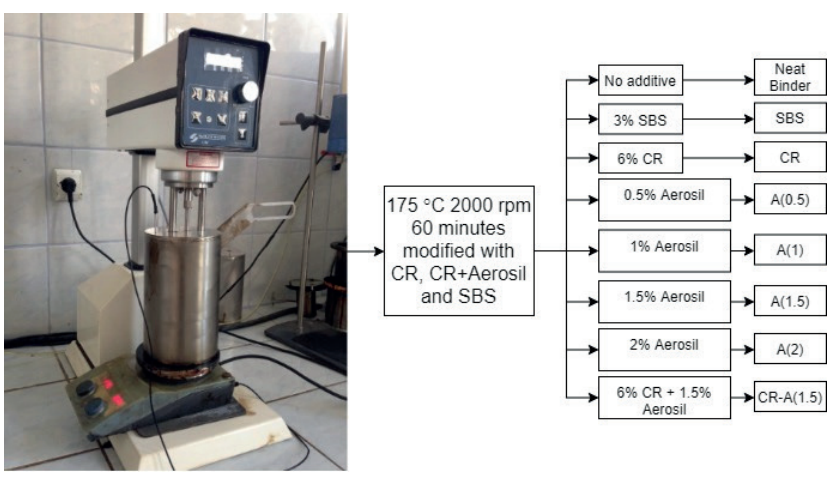

Fig. 1 Binder mixer and ID's used in study

Table 1 Properties of additives

\begin{tabular}{|c|c|c|c|c|c|}
\hline SBS & & \multicolumn{2}{|c|}{ Crumb rubber } & \multicolumn{2}{|l|}{$\begin{array}{l}\text { Fumed silica } \\
\text { (Aerosil 300) }\end{array}$} \\
\hline Properties & Value & \multicolumn{2}{|c|}{ Elemental analysis } & Properties & Value \\
\hline $\begin{array}{l}\text { Specific gravity } \\
\left(\mathrm{kg} / \mathrm{m}^{3}\right)\end{array}$ & 940 & $\mathrm{C}(\%)$ & 68.3 & $\begin{array}{l}\text { Surface area } \\
\left(\mathrm{m}^{2} / \mathrm{g}\right)\end{array}$ & 300 \\
\hline $\begin{array}{l}\text { Tensile strength } \\
\text { (psi) }\end{array}$ & 4600 & $\mathrm{H}(\%)$ & 7.1 & $\begin{array}{l}\text { Particle } \\
\text { diameter (nm) }\end{array}$ & 7 \\
\hline \multirow[t]{3}{*}{$\begin{array}{l}\text { Hardness shore } \\
\text { A }\end{array}$} & 69 & $\mathrm{~S}(\%)$ & 1.7 & $\begin{array}{l}\text { Tamped } \\
\text { density } \\
\left(\mathrm{kg} / \mathrm{m}^{3}\right)\end{array}$ & 55 \\
\hline & & $\mathrm{O}(\%)$ & 22.9 & $\begin{array}{l}\mathrm{SiO}_{2} \text { content } \\
(\%)\end{array}$ & 99.8 \\
\hline & & Ash (\%) & 3 & & \\
\hline
\end{tabular}
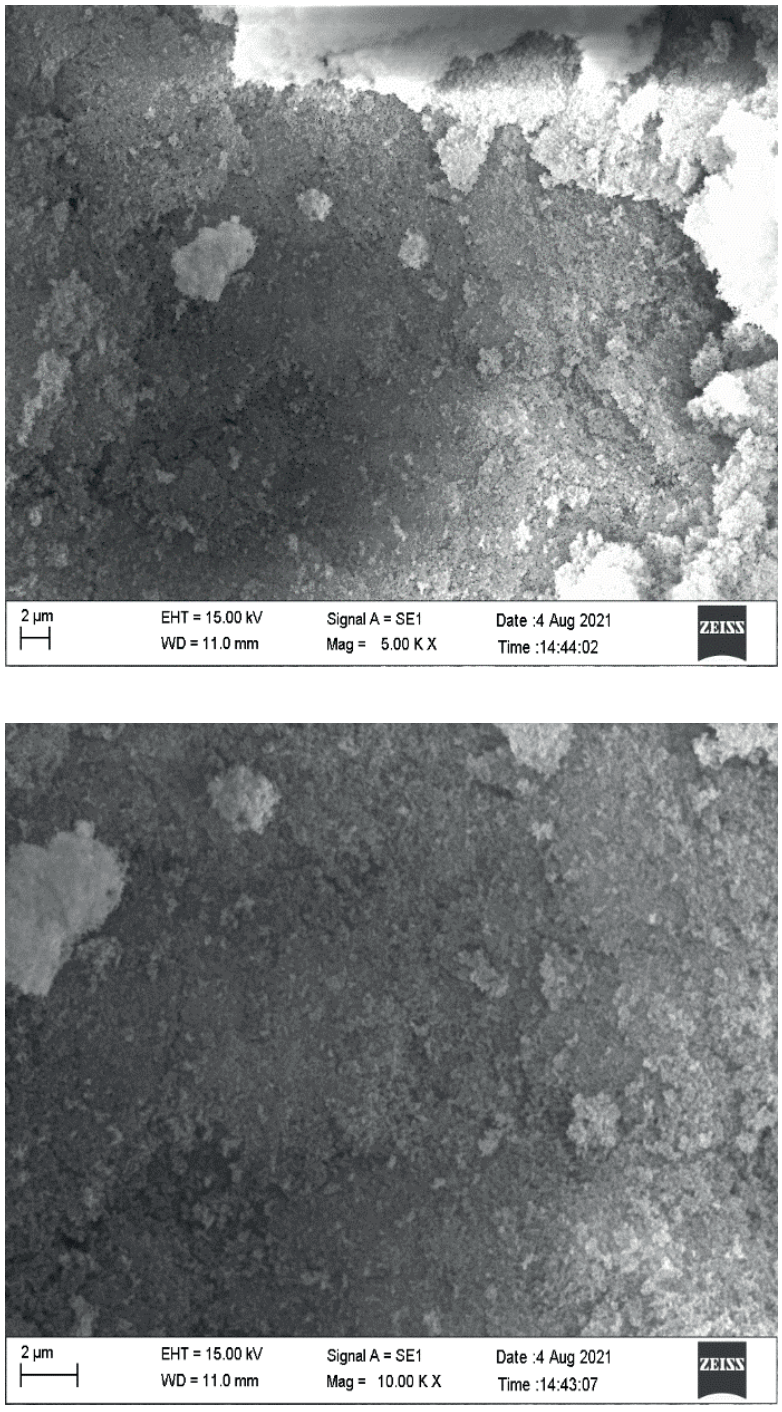

Fig. 2 SEM images of aerosil

The modified bitumens were produced with a high shear mixer (Fig. 1) at a temperature of $175^{\circ} \mathrm{C}$ for $1 \mathrm{~h}$ at a rotation speed of $2000 \mathrm{rpm}$.

\subsection{Experimental methods \\ 2.2.1 Softening point}

Softening point detection was performed to determine the sensitivity of bituminous binders to temperature changes and their resistance to high temperatures. The experiment was performed as per the AASHTO T53 standard [28].

\subsubsection{Rotational viscometer}

A rotational viscometer (RV) test was performed to find out the fluidity characteristics of bituminous binders under high temperatures $\left(135^{\circ} \mathrm{C}\right.$ and $\left.165^{\circ} \mathrm{C}\right)$. The test was performed using the DV-III Ultra Brookfield viscometer device per the criteria outlined in the AASHTO T 316 standard [29]. 
The viscosity values of the binders under high temperatures were used to determine the mixing-compaction temperatures of hot bituminous mixtures and they should not exceed $3000 \mathrm{cP}(3 \mathrm{~Pa} . \mathrm{s})$ at $135^{\circ} \mathrm{C}$ due to workability.

\subsubsection{Bending beam reometer}

A bending beam rheometer (BBR) test was performed to determine the low-temperature performance of bituminous binders. The test was carried out on unaged samples at $-25{ }^{\circ} \mathrm{C}$ as per the AASHTO T313 standard [30]. As a result of the test, the creep stiffness (St) and m-value values were determined, and the $\lambda$ value was found to identify the elasticity of the binders. The study [31] states that the flexible behavior under low temperatures develops at low creep stiffnesses having high m-values. Thus, the $\lambda$ value was obtained by dividing the creep stiffness by the $\mathrm{m}$-value for a more realistic evaluation. Low $\lambda$ values for elastic behavior under low temperatures were sought here.

\subsubsection{Frequency sweep test}

Frequency sweep tests were performed with Bohlin DSRII rheometer device at four different temperatures $\left(40{ }^{\circ} \mathrm{C}\right.$, $50{ }^{\circ} \mathrm{C}, 60^{\circ} \mathrm{C}$, and $70^{\circ} \mathrm{C}$ ) on a $25 \mathrm{~mm}$ parallel plate and with a gap geometry of $1 \mathrm{~mm}$. The test was carried out within the binder's linear viscoelastic (LVE) region. During the test, the frequency was adjusted to increase linearly within the range of $0.1-10 \mathrm{~Hz}$. The master curve of the complex modulus $\left(\mathrm{G}^{*}\right)$ and phase angle $(\delta)$ values obtained to determine the viscoelastic behavior in a wider frequency range at a reference temperature of $40^{\circ} \mathrm{C}$ was developed according to the time-temperature superposition principle (TTSP) with the Arrhenius equation given in Eq. (1).

$$
\log a_{T}=\frac{E_{a}}{R}\left(\frac{1}{T}-\frac{1}{T_{r e f}}\right)
$$

Here, $E_{a}$ is the relaxation-related activation energy, $R$ is the gas constant, $T$ is the test temperature, $T_{r e f}$ is the reference temperature, and $a_{T}$ is the shift factor. Just as the Arrhenius equation is used to describe the behavior outside the glass transition region, it is also referred to obtain the activation energy corresponding to the glass transition [32].

\subsubsection{FTIR}

Fourier transform infrared spectroscopy (FTIR) measurements were studied using the Shimadzu IRSpirit QATR-S instrument. FTIR analyses of the samples were made between $600 \mathrm{~cm}^{-1}$ and $4000 \mathrm{~cm}^{-1}$ wavelengths. Functional groups are very important in characterizing the materials in the chemical process. By comparing the functional groups of bitumen binders before and after modification, it can be determined whether chemical reactions or physical processes have occurred. There are two regions in the FTIR spectrum, namely the functional group region $\left(4000-1330 \mathrm{~cm}^{-1}\right)$ and the fingerprint region $\left(1330-400 \mathrm{~cm}^{-1}\right)$. The functional group region is used to define the functional group and therefore to determine the material structure.

\section{Results and discussions}

\subsection{Softening point and RV test results}

Fig. 3 shows the change in the softening points of neat and modified binders. As evident in Fig. 3, when the aerosil additive is solely used, the binder with $1.5 \%$ aerosil displays the highest softening point at $45.9{ }^{\circ} \mathrm{C}$, and this is $7.2 \%$ higher than the neat binder. Moreover, using the $1.5 \%$ aerosil together with $6 \% \mathrm{CR}$ brings about an increase of $10.6{ }^{\circ} \mathrm{C}, 2.9^{\circ} \mathrm{C}$, and $2.3^{\circ} \mathrm{C}$ in the softening points in comparison to the neat, $\mathrm{CR}$, and SBS-modified binders, respectively. It was seen that $\mathrm{CR}+$ aerosol modified binders with high softening point values will behave more rigidly and be harder compared to other binders. This is an indication that the binder will be more resistant to rutting and such deteriorations under high temperatures.

Table 2 shows the rotational viscosity test results. The viscosity values of the binder were marked on the viscosity-temperature graph and the temperature values that would provide the required viscosity values $(170 \pm 20 \mathrm{cP}$ and $280 \pm 30 \mathrm{cP}$, respectively) were determined during

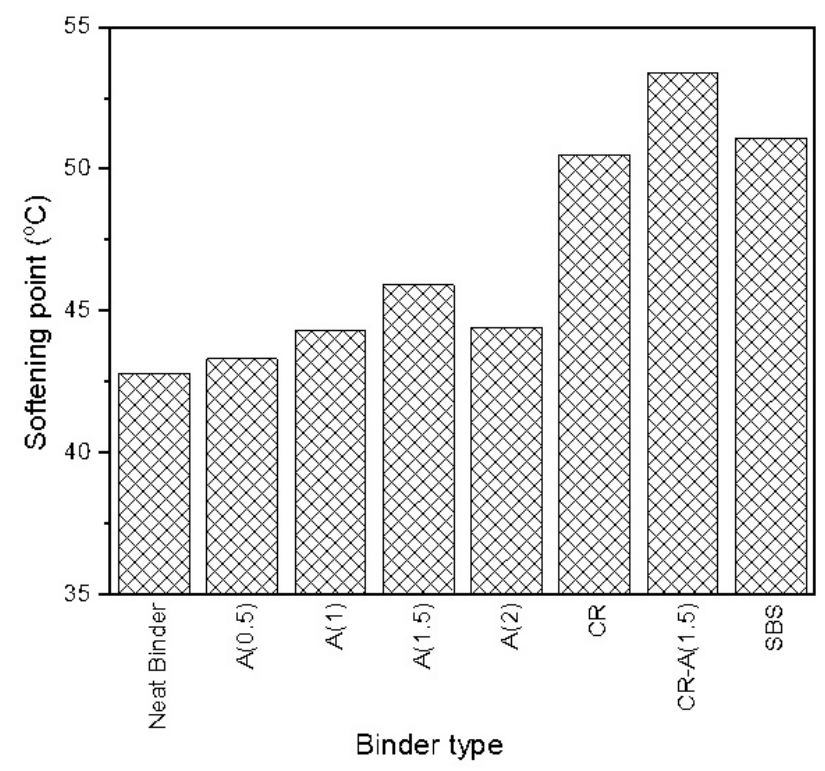

Fig. 3 Change in the softening point according to the binder type 
Table 2 Rotational viscosimeter test results

\begin{tabular}{|c|c|c|c|c|}
\hline \multirow{2}{*}{ Binder type } & \multicolumn{2}{|c|}{ Viscosity (cP) } & \multirow{2}{*}{$\begin{array}{c}\text { Mixing } \\
\text { temperatures }\left({ }^{\circ} \mathrm{C}\right)\end{array}$} & \multirow{2}{*}{$\begin{array}{c}\text { Compaction } \\
\text { Temperatures }\left({ }^{\circ} \mathrm{C}\right)\end{array}$} \\
\hline & $135^{\circ} \mathrm{C}$ & $165^{\circ} \mathrm{C}$ & & \\
\hline Neat Binder & 262.5 & 87.5 & $147-154$ & $127-137$ \\
\hline $\mathrm{A}(0.5)$ & 287.5 & 100 & $149-157$ & $131-141$ \\
\hline $\mathrm{A}(1)$ & 350 & 112.5 & $155-160$ & $140-147$ \\
\hline $\mathrm{A}(1.5)$ & 387.5 & 137.5 & $157-160$ & $142-148$ \\
\hline$A(2)$ & 362.5 & 125 & $161-165$ & $149-155$ \\
\hline $\mathrm{CR}$ & 812.5 & 250 & $168-170$ & $162-165$ \\
\hline CR-A(1.5) & 1438 & 437.5 & $172-173$ & $169-171$ \\
\hline SBS & 800 & 250 & $168-170$ & $162-165$ \\
\hline
\end{tabular}

mixing and compaction, in case of using bituminous binders in mixtures. Table 3 displays the viscosity-temperature relationship of the binders.

As Table 2 and Fig. 4 reveal, all binders are below the specification criterion of $3000 \mathrm{cP}$. Although there has been no significant increase in the viscosity of the neat binder when the aerosil additive was used solely, the viscosity increases approximately 5 times at both temperatures in comparison to the neat binder after using $1.5 \%$ aerosil with 6\% CR. This increase is nearly 3 times in CR and SBS modified binders. Consequently, it was determined that aerosil, CR, and SBS additives increase the consistency of the binder and raise the resistance to high temperatures.

\subsection{BBR test result}

Table 3 shows the results of the BBR test. According to the test results, when the aerosil additive is used alone, the stiffness $(\lambda)$ values respectively increase by $6.3 \%, 12.5 \%$, $6.9 \%$, and $4.9 \%$ in comparison to the pure binder at $0.5 \%$, $1 \%, 1.5 \%$, and $2 \%$, correspondingly. As Table 3 describes,

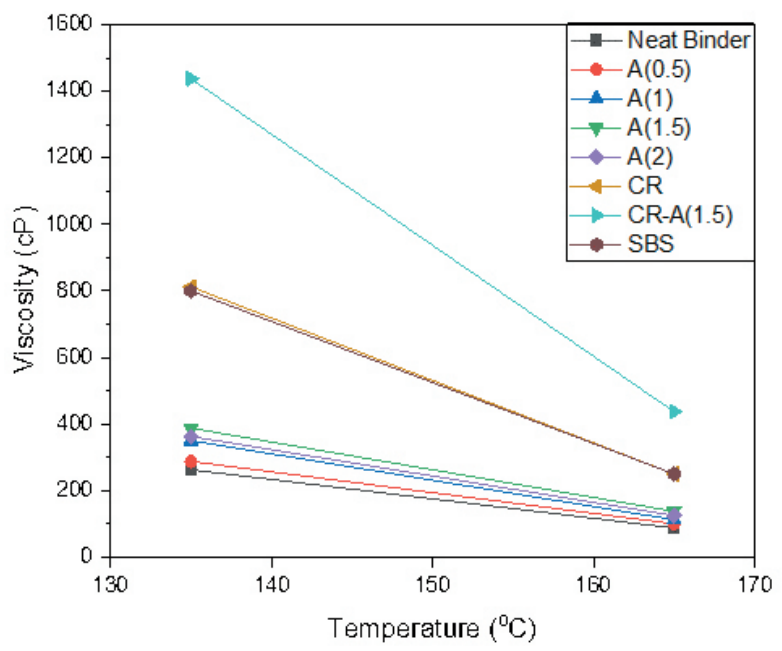

Fig. 4 The change in the viscosities of neat and modified binders by temperature
Table 3 BBR test result

\begin{tabular}{lccc}
\hline Binder type & $S t$ & $m$-value & $\lambda$ \\
\hline Neat Binder & 71.97 & 0.374 & 192.59 \\
A(0.5) & 74.23 & 0.361 & 205.62 \\
A(1) & 81.71 & 0.371 & 220.01 \\
A(1.5) & 74.05 & 0.358 & 206.84 \\
A(2) & 72.7 & 0.359 & 202.68 \\
CR & 89.19 & 0.309 & 288.55 \\
CR-A(1.5) & 78.02 & 0.306 & 255.13 \\
SBS & 88.45 & 0.279 & 316.91 \\
\hline
\end{tabular}

there occurs an increase of up to $1 \%$ in the creep stiffnesses compared to the neat binder with the use of aerosil, then they decrease and behave similarly with the pure binder under low temperature. $6 \% \mathrm{CR}$ and 3\% SBS modified binders display similar low-temperature behaviors. However, with the use of CR separately, the high creep stiffness value decreases by $14 \%$ with the use of $1.5 \%$ aerosil and it has no positive effect on the m-value. The $\lambda$ value of SBS-modified binder has the highest value among all modified binders. As a result, with the use of aerosil with CR, the binder behaves more flexibly at low temperatures and becomes more resistant to crack formations in comparison to the CR and SBS-modified binders.

\subsection{Frequency sweep test results}

Fig. 5 gives the complex modulus changes at frequencies of $0.1,1,5$, and $10 \mathrm{~Hz}$ under $40^{\circ} \mathrm{C}$. As the figure shows, the highest complex modulus $\left(\mathrm{G}^{*}\right)$ value was determined to be given by the binder with $1.5 \%$ aerosil additive at all frequencies when the aerosil additive was used alone. $\mathrm{CR}+$ aerosil modified binders gave the highest $\mathrm{G}^{*}$ values at all frequencies, while the neat binders had the lowest $G^{*}$

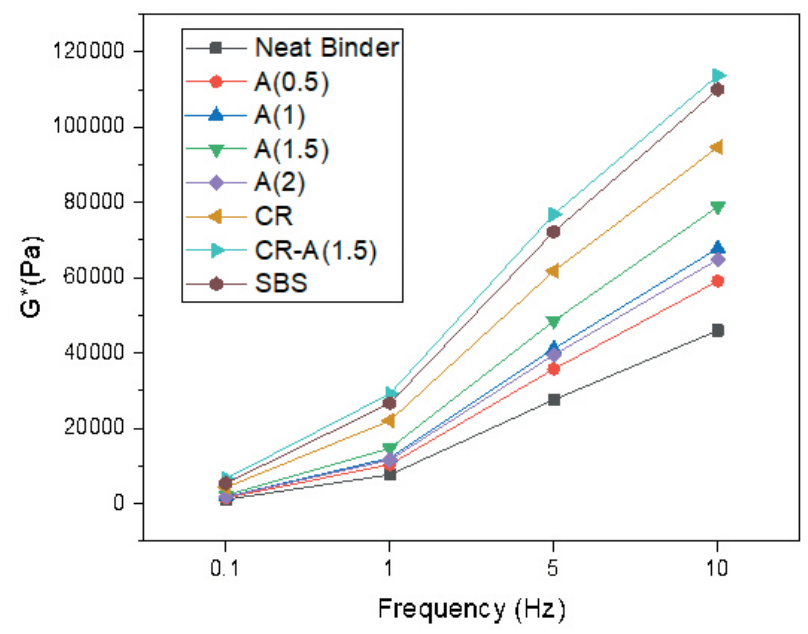

Fig. 5 The effect of frequency change on the complex modulus at $40{ }^{\circ} \mathrm{C}$ 
values. When $6 \% \mathrm{CR}$ and $1.5 \%$ aerosil additive were used together, $6.15,3.01,1.54$, and 1.23 times higher $\mathrm{G}^{*}$ values were obtained at $0.1 \mathrm{~Hz}$ frequency in comparison to the neat, $1.5 \%$ aerosil, CR, and SBS added binders, respectively; and these ratios were 2.47, 1.44, 1.20, and 1.04 at $10 \mathrm{~Hz}$. The effectiveness of modified binders became more obvious at low frequency or under adverse loading conditions such as prolonged loading. $\mathrm{CR}+$ aerosil added binders with high complex modulus values were observed to be more resistant to rutting at high temperatures.

Fig. 6 shows the variation of the complex modulus values of neat and modified binders at different frequencies with temperature. As the figure reveals, when the aerosil additive is used alone, $1.5 \%$ aerosil added binders at $40{ }^{\circ} \mathrm{C}$ and $50{ }^{\circ} \mathrm{C}$ at all frequency values display higher complex modulus values compared to other ratios, while $2 \%$ aerosil additives at $60{ }^{\circ} \mathrm{C}$ and $70{ }^{\circ} \mathrm{C}$ give high complex modulus values. Thus, it was determined that rather than the frequency values, the temperature values are more effective on the aerosil contribution in terms of $\mathrm{G}^{*}$ values. While $6 \%$ $\mathrm{CR}+1.5 \%$ aerosil added binder gives the highest $\mathrm{G}^{*}$ value at all frequencies and temperatures, the $\mathrm{G}^{*}$ values of $\mathrm{CR}$ and SBS modified binders get closer to those of $\mathrm{CR}+$ aerosil added binders as the frequency value raises. Besides, the use of aerosil together with CR drove up the complex modulus values of the CR modified binders above the SBSmodified binder' values

Fig. 7 gives the variation of phase angles of neat and modified binders with the temperature at frequencies of 0.1 , 1,5 , and $10 \mathrm{~Hz}$. When using the aerosil alone as a modifier, it provides $1.5 \%$ lower phase angle values at all frequencies at $40{ }^{\circ} \mathrm{C}$ and $2 \%$ lower phase angle values at $50{ }^{\circ} \mathrm{C}, 60{ }^{\circ} \mathrm{C}$, and $70{ }^{\circ} \mathrm{C}$ and behaves more flexibly. Just like the variation in the complex modules in Fig. 6, it can be seen here that the temperature factor is effective on the aerosil additive. $6 \% \mathrm{CR}+1.5 \%$ aerosil-modified binders displayed the lowest phase angle values at high frequencies (Figs. 7(c) and (d)). For example, at $60^{\circ} \mathrm{C}, \mathrm{CR}+$ aerosil-doped binders displayed $15.3{ }^{\circ} \mathrm{C}, 3.6{ }^{\circ} \mathrm{C}$, and $4.5^{\circ} \mathrm{C}$ lower phase angle values at $5 \mathrm{~Hz}$ respectively, compared to the neat, $\mathrm{CR}$ and SBS modified binders; while at $10 \mathrm{~Hz}$, these ratios were $15.6{ }^{\circ} \mathrm{C}, 3.5^{\circ} \mathrm{C}$, and $3.2^{\circ} \mathrm{C}$.
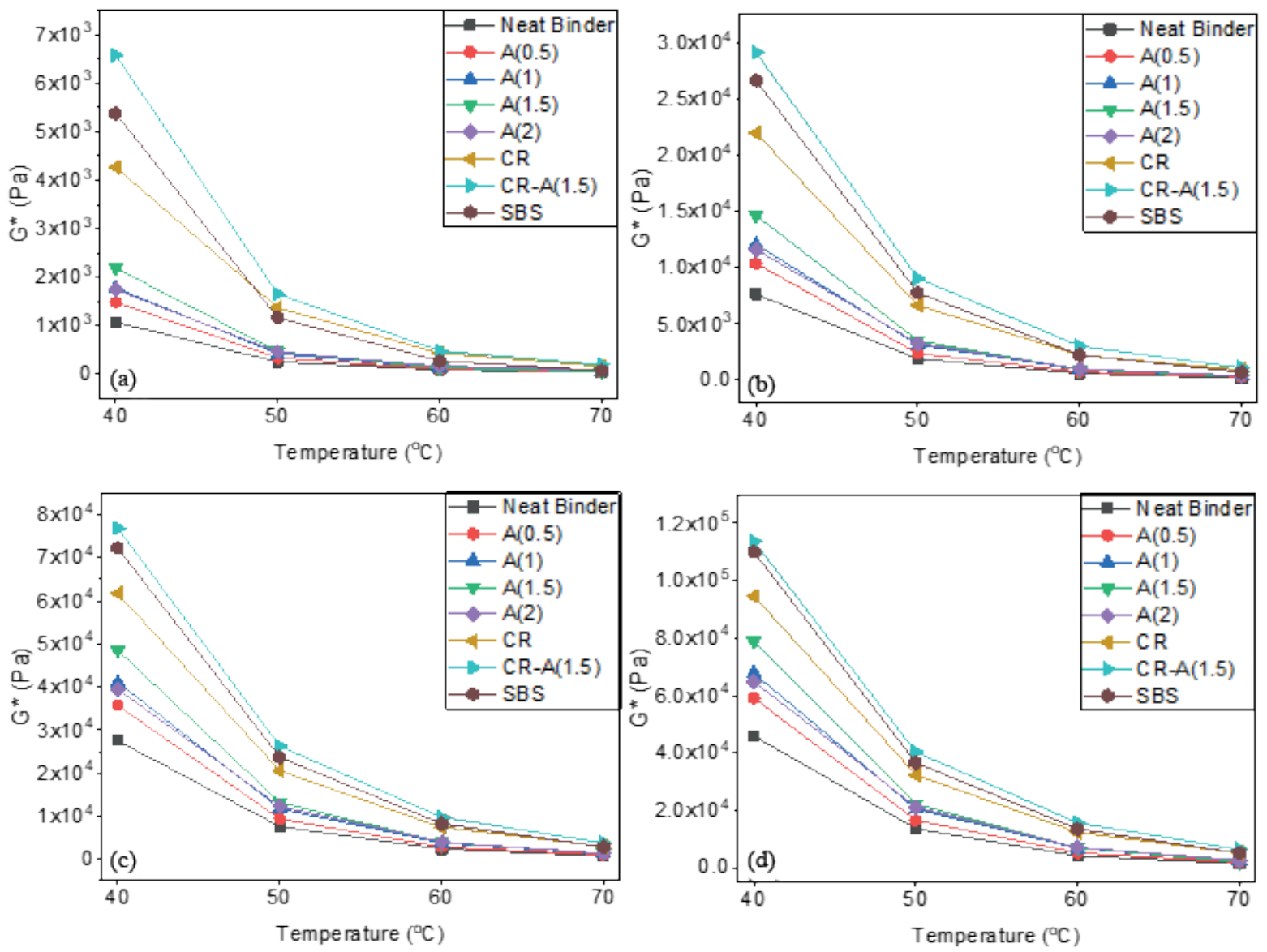

Fig. 6 The variation of $\mathrm{G}^{*}$ values by the temperature at different frequencies (a) $0.1 \mathrm{~Hz}$, (b) $1 \mathrm{~Hz}$, (c) $5 \mathrm{~Hz}$, (d) $10 \mathrm{~Hz}$ 

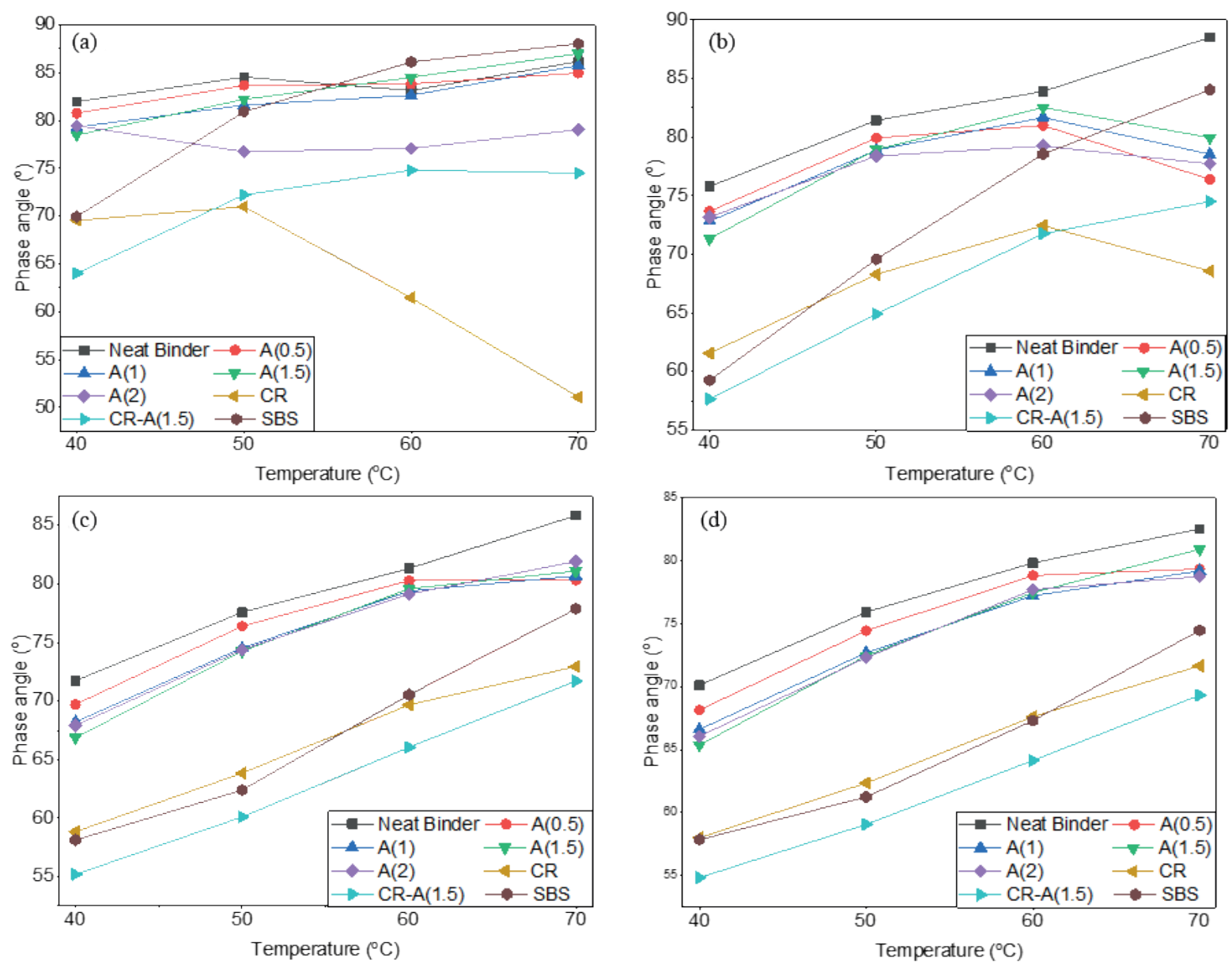

Fig. 7 The variation of phase angle by the temperature at different frequencies (a) $0.1 \mathrm{~Hz}$, (b) $1 \mathrm{~Hz}$, (c) $5 \mathrm{~Hz}$, (d) $10 \mathrm{~Hz}$

Fig. 8 shows the master curves at a reference temperature of $40{ }^{\circ} \mathrm{C}$ according to TTSP. When examining the rheological properties of asphalt binders, knowing the rheological properties at low, medium, and high frequencies provides information on how the pavement will behave at different vehicle speeds. Fig. 8 indicates that the complex

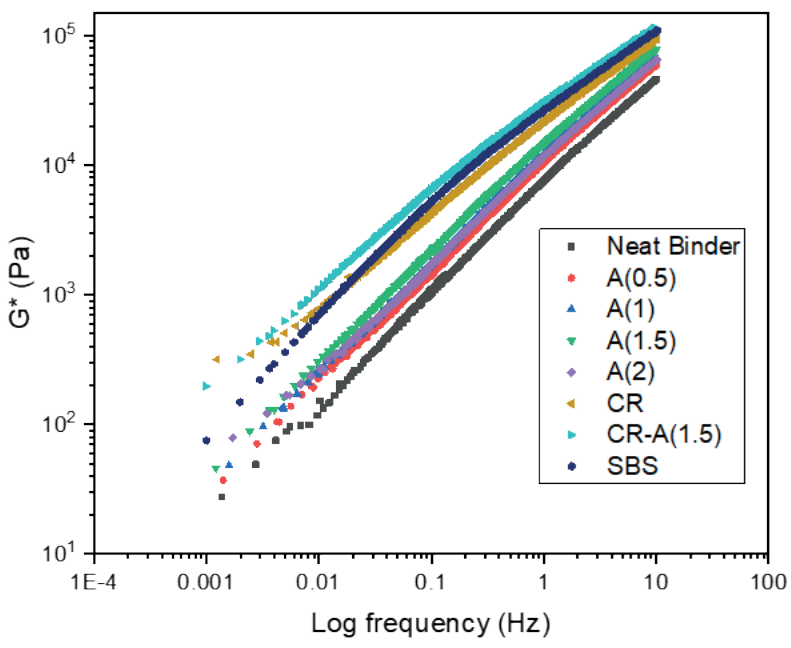

Fig. 8 Master curve of Complex modulus (Master Curve at $40{ }^{\circ} \mathrm{C}$ ) shear modulus of all binders increases logarithmically with the increase in frequency. When the aerosil additive is used alone, binders with $1.5 \%$ aerosil additive exhibit the highest complex shear modulus values. Thus, $1.5 \%$ was found to be the most suitable aerosil ratio. Among all binders, $6 \%$ $\mathrm{CR}+1.5 \%$ aerosil-modified binder performed the highest complex shear modulus, while the lowest $G^{*}$ values were displayed by the neat binder. It was determined that the rheological properties of the neat binder will improve more than the SBS modified binder by using CR and aerosil additive together at both low and high-frequency values (in other words, under low and high vehicle speeds).

Fig. 9 shows the change of phase angles of neat and modified binders according to the frequency. As Fig. 9 indicates, CR modified binders reveal the lowest phase angle values at low frequencies (from $0.01 \mathrm{~Hz}$ to $0.03 \mathrm{~Hz}$ ). However, after $0.1 \mathrm{~Hz}$ frequency, $\mathrm{CR}$ and aerosil-modified binders behave more flexibly by revealing a lower phase angle. While the neat binder reveals the highest phase angle values at all frequencies, aerosil-modified binders give similar values among themselves. The use of aerosil with $\mathrm{CR}$ 


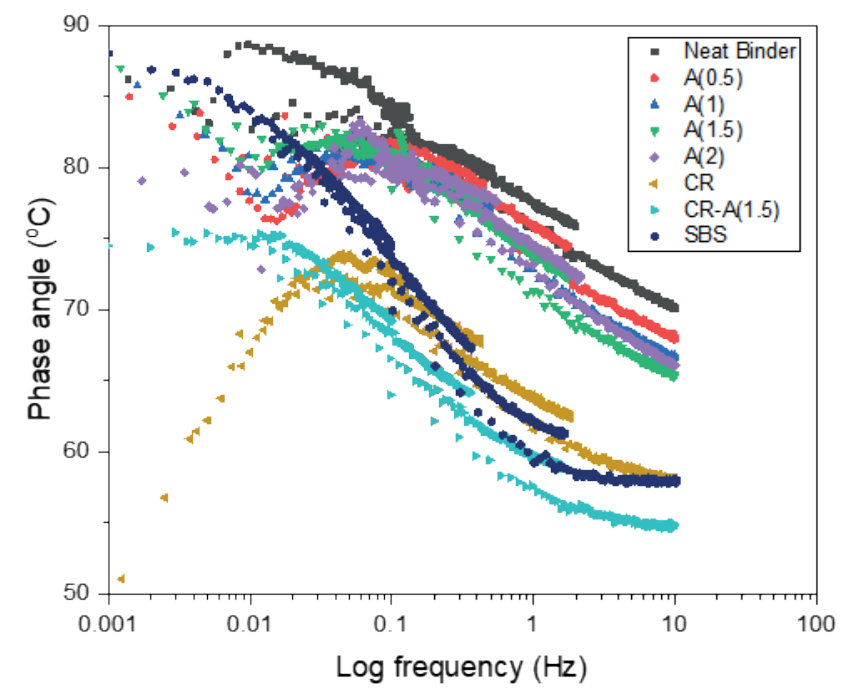

Fig. 9 Master curve of phase angle

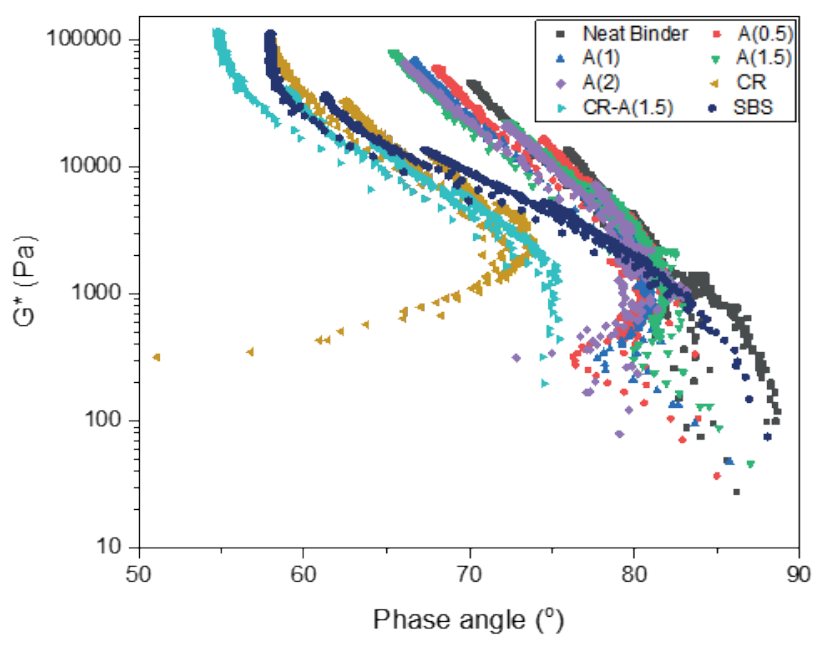

Fig. 10 Black diagram for neat and modified binders

creates a significant reduction in phase angles. Besides, after $0.1 \mathrm{~Hz}$ frequency, SBS and CR modified binders put in similar performances in terms of phase angle values.

Fig. 10 gives a black space diagram of neat and modified binders drawn by using TTSP and frequency scan data. The black space diagram indicates the phase angle corresponding to the complex shear modulus from dynamic rheological data. This plot is stated to be typically used for measuring the validity of time-temperature superposition and thermorheological simplicity [33]. As the figure indicates, the time-temperature superposition of the CR-modified binders disappears above $60{ }^{\circ} \mathrm{C}$, referring that the CR modification has a thermorheologically complex structure under high temperatures. However, the addition of the aerosil additive to the CR modification reduces the deviation in the time-temperature superposition (TTS). SBS modified binder shows TTS valid over CR and aerosil modified binders [34]. Aerosil-modified binders also put up similar properties in terms of TTS. Besides, below $1000 \mathrm{~Pa}$ complex modulus values after $60^{\circ} \mathrm{C}$, aerosil-modified binders behave more flexibly by displaying lower phase angle values than SBS-modified binders.

Fig. 11 gives the Cole-Cole diagram of neat and modified binders. As the figure shows, the curves of CR, SBS, and $\mathrm{CR}+$ aerosil-modified binders shear towards the storage modulus. This is an indication that these binders behave more flexibly according to other ones. Besides, $\mathrm{CR}+$ aerosil modified binder exhibits a more flexible behavior than SBS-modified binder under low frequency and high temperatures.

\subsection{FTIR spectrum for Aerosil modified bitumen}

In the FTIR spectrum, 2921 and $2850 \mathrm{~cm}^{-1}$ correspond to the $\mathrm{CH} 2$ and $\mathrm{CH} 3$ stretch in bitumen (alkanes), while the $\mathrm{C}=\mathrm{C}$ stretch shows the aromatic groups at $1600 \mathrm{~cm}^{-1}$ wavelength. The peaks between 1467 and $1378 \mathrm{~cm}^{-1}$ wavelengths represent $\mathrm{CH} 3$ asymmetric and symmetric deformation (alkanes), respectively. The peak of nanosilica particles at $1050 \mathrm{~cm}^{-1}$ wavelength refers to the Si-O-Si bond, which is the backbone of silicon for the silica modified surface. However, it has been determined that this peak shifted towards a wavelength of $1100 \mathrm{~cm}$ in the bitumen binder modified with nanosilica. This shift indicates that the modified bitumen is obtained by interacting with the siloxane bond of the bitumen with the nanosilica particle. This proves the physical interaction that occurs as a result of the modification in bitumen. The surface of pure nanosilica contains silanols that support the formation of hydrogen bonds with asphaltenes in bitumen.

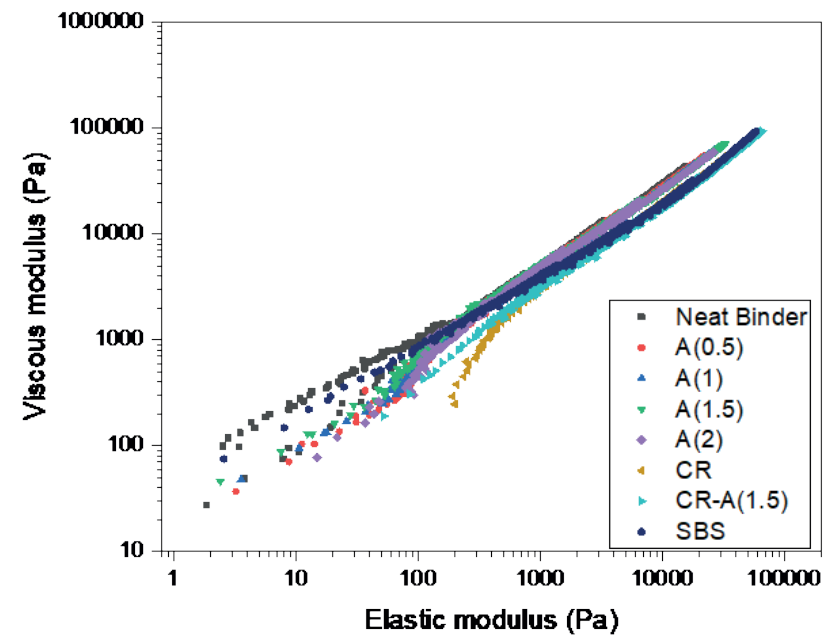

Fig. 11 Cole-Cole diagram for neat and modified binders measured at a reference temperature $40{ }^{\circ} \mathrm{C}$ 
It has been observed that the surface of pure nanosilica has silanols and it promotes the formation of hydrogen bonds with asphaltenes in bitumen, thus demonstrating the physical interaction between the functional groups in the bitumen and the nanosilica [35-38]. In the FTIR spectrum in Fig. 12, Si-O-Si asymmetric bonds are seen at $1087 \mathrm{~cm}^{-1}$ and $\mathrm{Si}-\mathrm{O}-\mathrm{Si}$ symmetric bonds at $809 \mathrm{~cm}^{-1}$ wavelengths. When the spectrum is examined, as the ratio of aerosil (wt.\%) in the modified bitumen increases, the size of the Si-O-Si peak observed at a wavelength of $809 \mathrm{~cm}^{-1}$ rises as well. Similarly, the intensity of the peak at $1087 \mathrm{~cm}^{-1}$ wavelength also increases. It has been determined that aerosil, which interacts physically with bitumen, did not bond with a chemical reaction.

The FTIR spectrum in Fig. 13 shows the FTIR image of aerosil 300, pure bitumen, crumb rubber (6wt.\%) modified bitumen, and aerosil (1.5wt.\%) with crumb rubber (6wt.\%) modified bitumen. It was found that aerosil 300 reinforcement in the spectrum increased the intensity of the peaks at $810 \mathrm{~cm}^{-1}$ and $1100 \mathrm{~cm}^{-1}$ wavelengths. Although a chemical reaction was not among the components, it was considered that there could be physical changes in the structure.

\subsection{Response surface methodology (RSM)}

In this study, an experimental design was made with statistical regression according to RSM method and optimum conditions were evaluated according to response functions. In the experimental design, it is necessary to determine the effective parameters to find optimum results with a small number of experiments. The response functions of these parameters in the process are defined

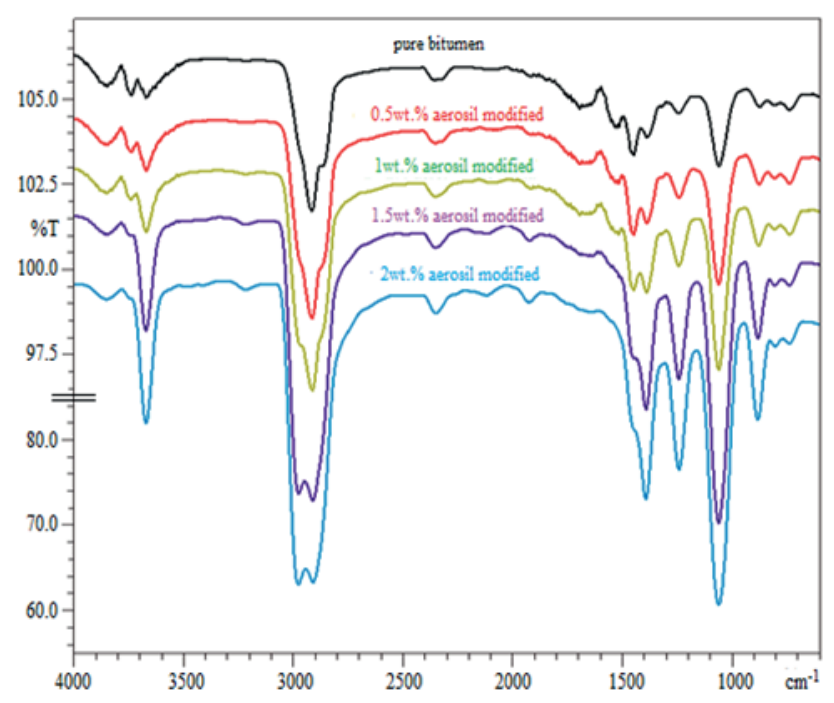

Fig. 12 FTIR spectrum of the pure and aerosil modified bitumen statistically in a fast, reliable way, yielding a good solution. According to the RSM method, the most appropriate results are obtained in the most economical way, in a short time and with maximum efficiency by sparing less effort. In the experiments, optimum results were obtained by evaluating the response functions of the independent variables. First, the independent variables and their range of change were defined, and then the experimental results obtained were entered into the RSM as a response function. The results were defined by statistical analysis, and both optimum experimental conditions and optimum mixing ratios were evaluated [39-42]. In Fig. 14, the complex modulus, effect of temperature and aerosil 300 ratio (wt.\%) are shown according to the RSM results. In Fig. 15, both the agreement and the distribution of the deviations between the actual data and the predicted values were evaluated according to the experimental study plan. In the experiments, optimum results were obtained by evaluating the response functions of the independent variables. First, the independent variables and their range of change were defined, and then the experimental results obtained were entered into the RSM as a response function. The results were defined by statistical analysis, and both optimum experimental conditions and optimum mixing ratios were evaluated [39-42]. In Fig. 14, the complex modulus, effect of temperature and aerosil 300 ratio (wt.\%) are shown according to the RSM results. In Fig. 15, both the agreement and the distribution of the deviations between the actual data and the predicted values were evaluated according to the experimental study plan.

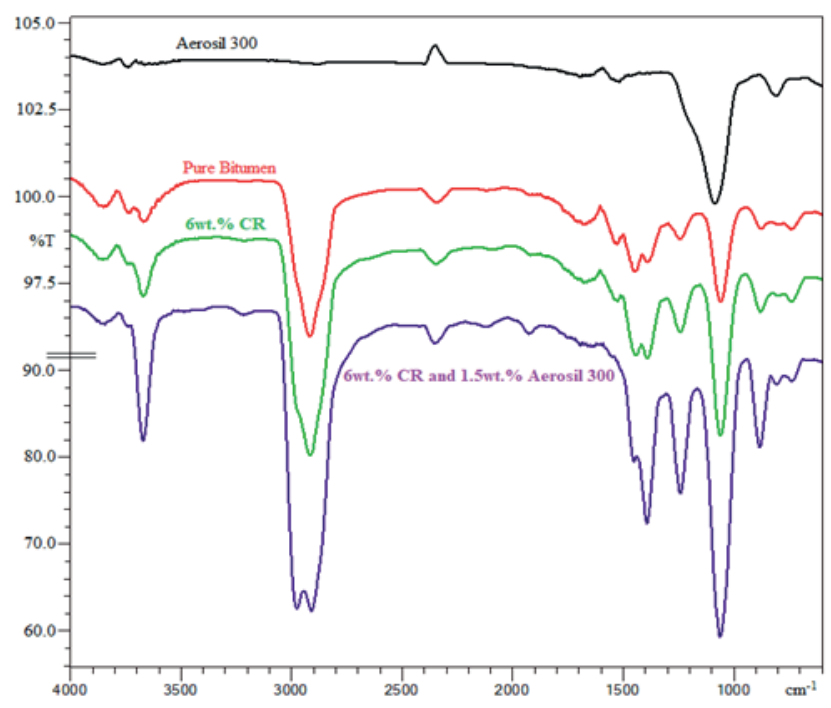

Fig. 13 FTIR spectrum of the crumb rubber and aerosil modified bitumen 

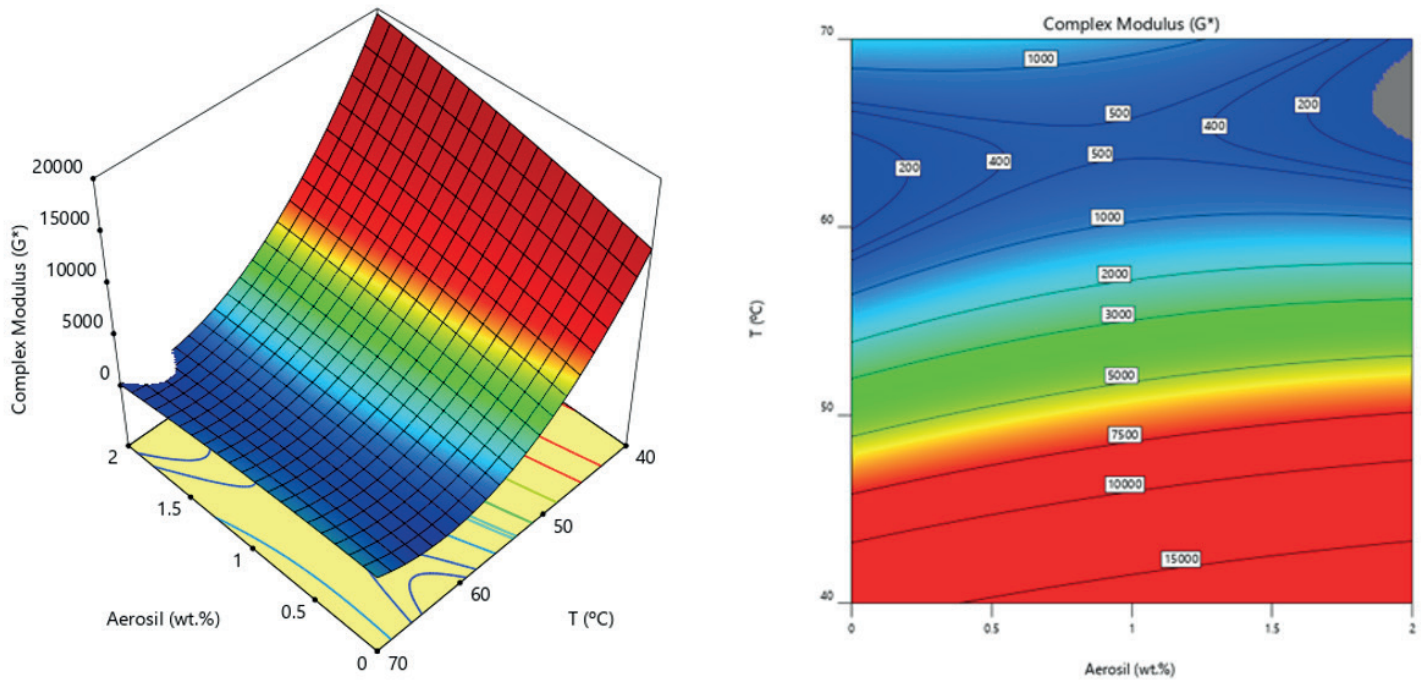

Fig. 14 Change of complex modules $\left(\mathrm{G}^{*}\right)$ with temperature and aerosil ratio (wt.\%) for the power model
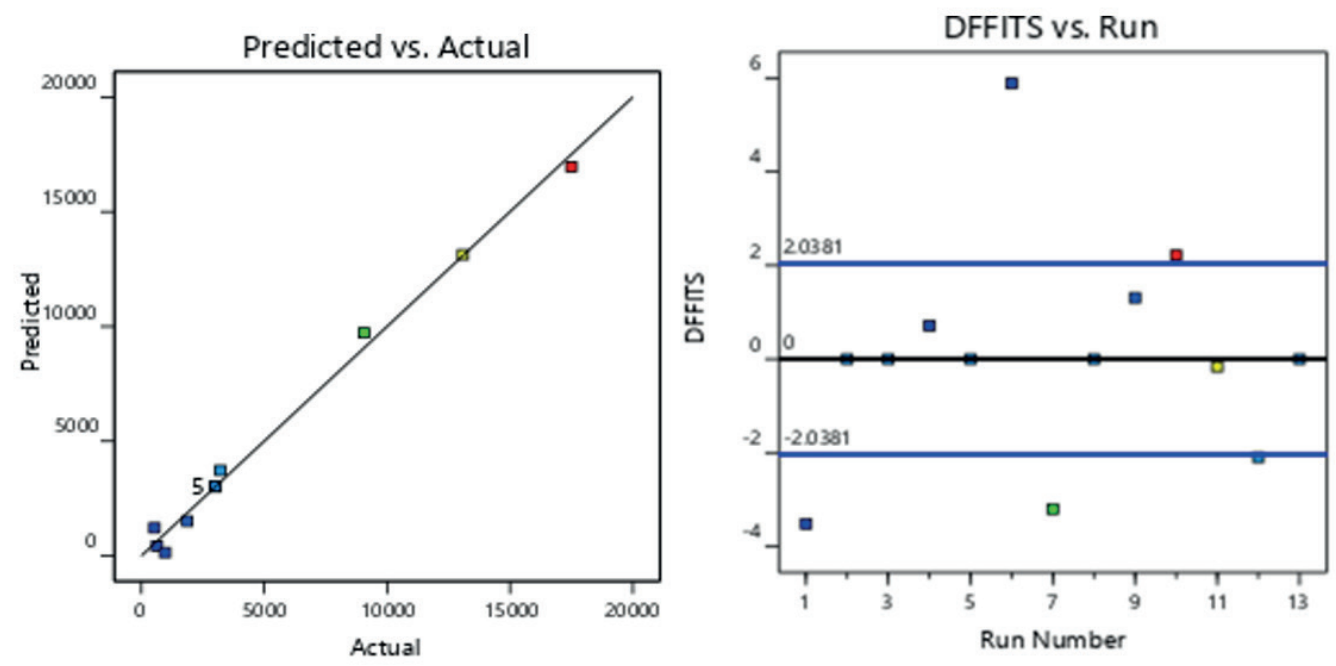

Fig. 15 Statistical analysis for the RSM results for power model

Fig. 16 shows the effect of temperature and aerosil ratio (wt.\%) on the complex modulus in the RSM results obtained using the Square Root model. In Fig. 17, both the agreement and the distribution of the deviations between the actual data and the predicted values were determined according to the square root model.

In Eq. (2) and Eq. (3), the aerosil rate (A: wt.\%), temperature $\left(\mathrm{T}\right.$ : $\left.{ }^{\circ} \mathrm{C}\right)$, and complex modulus $\left(\mathrm{G}^{*}\right)$ have been expressed in the RSM model equations.

$$
\begin{aligned}
G^{*}= & +1.05300+8668.96473 \cdot A \\
& -3372.07145 \cdot T-123.08767 \cdot A \cdot T \\
& -397.49625 \cdot A^{2}+27.00224 \cdot T^{2} \\
\sqrt{G^{*}} & =+541.86929+39.58541 \cdot A \\
& -14.94071 \cdot T-0.445651 \cdot A \cdot T \\
& -3.64927 \cdot A^{2}+0.106907 \cdot T^{2}
\end{aligned}
$$

In validation experiments, the aerosil ratio was taken as 1wt. $\%$ and the temperature as $55^{\circ} \mathrm{C}$, and the experiments were repeated for 5 times. According to the experimental data, complex modulus were found to be approximately 3020, 2998, 3045, 3012, and 3029. In the RSM method, the results were expressed in the lowest 2959.70 and the highest 3083.09 at $95 \%$ confidence interval. Statistical analysis $($ Std. $\mathrm{dev}=41.2579)$ indicated that the experimental data and the theoretical results were consistent. RSM analysis of variance (ANOVA) results and statistical data are shown in Table 4. The statistical significance of the model equations can be determined by the P-test and the significance value by the F-test. P-value $(<0.0001)$ and F-value were evaluated by statistical analysis of complex modulus, temperature, and amount of aerosil (wt.\%) in the RSM study plan. Low F-value and P-value tests indicate high significance for the regression model. Besides, the suitability of the model 

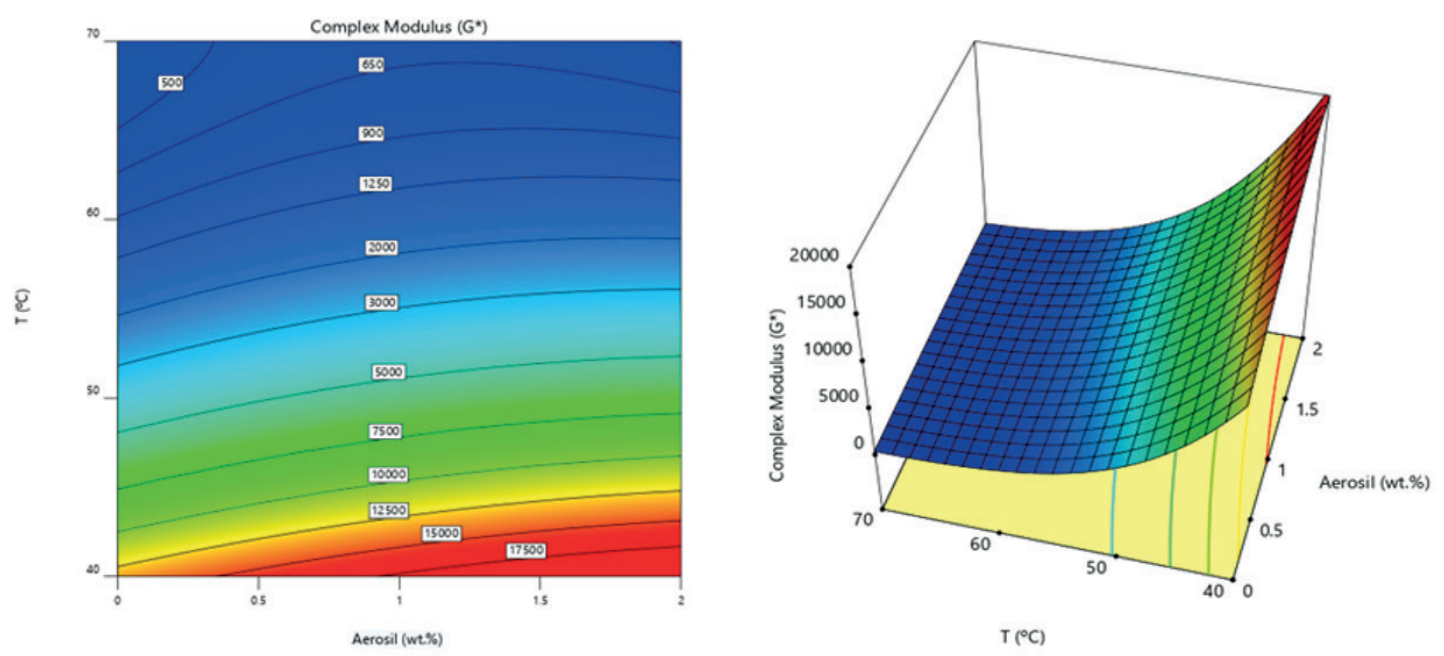

Fig. 16 Change of complex modules $\left(G^{*}\right)$ with temperature and aerosil ratio (wt.\%) for the square root model
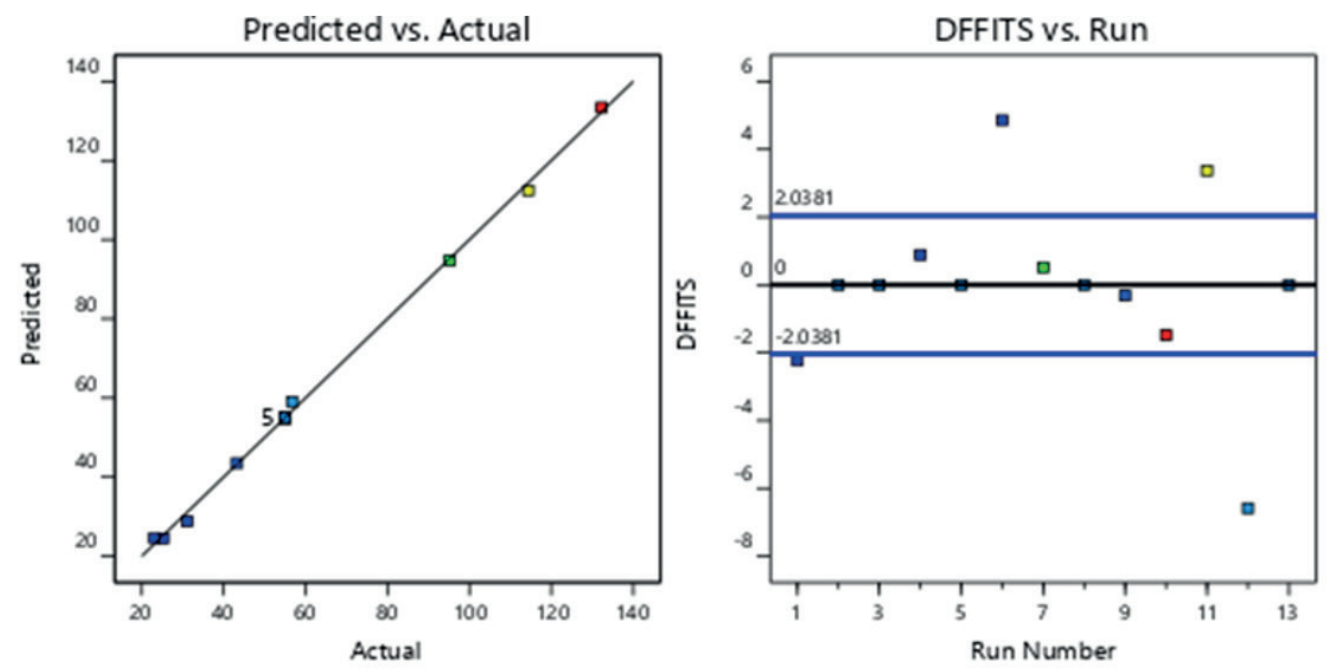

Fig. 17 Statistical analysis for the RSM results for square root model

Table 4 RSM design models result for the complex modulus

\begin{tabular}{lccccccc}
\hline Transform & Source & P-value & F-value & SST & Std. Dev. & R $^{2}$ & C.V.\% \\
\hline Power & Quadratic & 0.0001 & 102.14 & 108.78 & 1.63 & 0.9986 & 2.66 \\
Square Root & Quadratic & 0.0001 & 215.51 & 219.67 & 1.98 & 0.9979 & 3.82 \\
\hline
\end{tabular}

can also be explained by the fact that the multiple correlation coefficients $\left(\mathrm{R}^{2}\right)$ are close to 1 . It is stated that the value of the predicted correlation coefficient and the adjusted correlation coefficient value are also congruent. Also, the lower coefficient of variance (\%C.V.) indicates a better precision and reliability of the experiments performed [41-43].

According to the RSM results, optimum experimental conditions are $1 \mathrm{wt} . \%$ aerosil rate, $55^{\circ} \mathrm{C}$ temperature, and 3019.5 complex modulus.

The distribution of the experimental data and the model data were compared according to the RSM results in Fig. 16. The data obtained in the experimental study plan in RSM design according to the central composite method were evaluated by statistical analysis. In the central region, the distribution of errors, large deviations, and small deviations were defined, and the consistency of the actual and estimated values were evaluated. According to the statistical parameters, the fact that the error functions such as total sum square (SST) were low indicates the reliability of the experimental model and its consistency with the theoretical model [43-46]. 


\section{Conclusions}

This study examines the effect of the binder on high and low-temperature parameters in the case of using the aerosil additive alone and together with $\mathrm{CR}$ and compares it to the SBS modified binder.

1. The softening point test results show that the use of $1.5 \%$ aerosil additive causes an increase of approximately $3{ }^{\circ} \mathrm{C}$ in the softening point of both neat and CR-modified binders.

2. It was found that aerosil, CR, and SBS additives increase the consistency of the binder and decrease its fluidity under high temperatures.

3. BBR test results reveal that the use of aerosil together with CR makes the binder behave more flexibly under low temperatures and more resistant to crack formation in comparison to the binders with CR and SBS additives.

\section{References}

[1] Favakeh, M., Bazgir, S., Karbasi, M., Alavi, M. Z., Abdi, A. "Evaluation of elastomer-plastomer vulcanised modifiers for using as bitumen binder modifier", International Journal of Pavement Engineering, 2020.

https://doi.org/10.1080/10298436.2020.1736292

[2] Behnood, A., Shah, A., McDaniel, R. S., Beeson, M., Olek, J. "HighTemperature Properties of Asphalt Binders: Comparison of Multiple Stress Creep Recovery and Performance Grading Systems", Transportation Research Record: Journal of the Transportation Research Board, 2574(1), pp. 131-143, 2016.

https://doi.org/10.3141/2574-15

[3] Behnood, A., Olek, J. "Rheological properties of asphalt binders modified with styrene-butadiene-styrene (SBS), ground tire rubber (GTR), or polyphosphoric acid (PPA)", Construction and Building Materials, 151, pp. 464-478, 2017.

https://doi.org/10.1016/j.conbuildmat.2017.06.115

[4] Kisgyörgy, L., Tóth, C., Geiger, A. "Elastic modulus of asphalt with chemically stabilized rubber bitumen", Građevinar, 68(7), pp. 533$541,2016$.

https://doi.org/10.14256/JCE.1451.2015

[5] Lin, P., Huang, W., Tang, N., Xiao, F. "Performance characteristics of Terminal Blend rubberized asphalt with SBS and polyphosphoric acid", Construction and Building Materials, 141, pp. 171-182, 2017. https://doi.org/10.1016/j.conbuildmat.2017.02.138

[6] Wang, H., You, Z., Mills-Beale, J., Hao, P. "Laboratory evaluation on high temperature viscosity and low temperature stiffness of asphalt binder with high percent scrap tire rubber", Construction and Building Materials, 26(1), p. 583-590, 2012.

https://doi.org/10.1016/j.conbuildmat.2011.06.061

[7] Almusawi, A., Sengoz, B., Topal, A. "Investigation of mixing and compaction temperatures of modified hot asphalt and warm mix asphalt", Periodica Polytechnica Civil Engineering, 65(1), pp. 72-83, 2021.

https://doi.org/10.3311/PPci.15118
4. Frequency sweep results indicate that $\mathrm{CR}+$ aerosil modified binders behave more flexibly and reveal higher complex modulus values than SBS and CR modified binders under all frequencies and temperatures.

5. Statistical analysis reveal that the experimental data and the theoretical data obtained from the RSM method are coherent.

6. FTIR results show that the use of aerosil alone or aerosil supplementation to the $\mathrm{CR}$ modification increases the intensity of the peaks at $810 \mathrm{~cm}^{-1}$ and $1100 \mathrm{~cm}^{-1}$ wavelengths. It was estimated that physical changes may occur in the structure although there is no chemical reaction between the components.

7. According to RSM results, optimum experimental conditions are $1 \mathrm{wt} . \%$ aerosol rate and $55^{\circ} \mathrm{C}$ temperature.

[8] Kök, B. V., Çolak, H. "Laboratory comparison of the crumb-rubber and SBS modified bitumen and hot mix asphalt", Construction and Building Materials, 25(8), pp. 3204-3212, 2011.

https://doi.org/10.1016/j.conbuildmat.2011.03.005

[9] Kök, B. V., Yilmaz, M., Akpolat, M. "Effect of CR and FT-paraffin versus SBS modification in terms of conventional and rheological properties", International Journal of Pavement Engineering, pp. 1052-1059, 2016.

https://doi.org/10.1080/10298436.2016.1149832

[10] Raufi, H., Topal, A., Sengoz, B., Kaya, D. "Assessment of asphalt binders and hot mix asphalt modified with nanomaterials", Periodica Polytechnica Civil Engineering, 64(1), pp. 1-13, 2020. https://doi.org/10.3311/PPci.14487

[11] Cheraghian, G., Wistuba, M. P. "Ultraviolet aging study on bitumen modified by a composite of clay and fumed silica nanoparticles", Scientific Reports, 10(1), Article number: 11216, 2020.

https://doi.org/10.1038/s41598-020-68007-0

[12] Cheraghian, G., Wistuba, M. P. "Effect of Fumed Silica Nanoparticles on Ultraviolet Aging Resistance of Bitumen", Nanomaterials, 11(2), Article number: 454, 2021. https://doi.org/10.3390/nano11020454

[13] Xia, T., Chen, X., Xu, J., Li, Y., Zhang, A. "Influence of hydrophilic nanosilica premixing method on the property of isocyanate-based polymer modified bitumen", Construction and Building Materials, 275, Article number: 122174, 2021.

https://doi.org/10.1016/j.conbuildmat.2020.122174

[14] Taherkhani, H., Afroozi, S. "Investigating the creep properties of asphaltic concrete containing nano-silica", Sādhanā, 43(2), Article number: 24, 2018.

https://doi.org/10.1007/s12046-018-0792-3

[15] Zghair, H. H., Jony, H., Hassan, M. "Rheological Characteristics of Nano Silica Modified Asphalt Binder Material", In: 2019 International Engineering Conference (IEC), Erbil, Iraq, 2019, pp. 79-84. https://doi.org/10.1109/IEC47844.2019.8950636 
[16] Anaclet, P., Julien, V., Mariotti, S., Backov, R., Schmitt, V. "Development of dispersible and flowable powdered bitumen", Journal of Cleaner Production, 141, pp. 940-946, 2017. https://doi.org/10.1016/j.jclepro.2016.09.110

[17] Al-Yasari, R., Al-Busaltan, S. "The effects of reed fly ash modified bitumen on the volumetric and mechanical properties of open grade friction course mixtures", IOP Conference Series: Materials Science and Engineering, 1067(1), Article number: 012075, 2021. https://doi.org/10.1088/1757-899X/1067/1/012075

[18] Motamedi, M., Shafabakhsh, G., Azadi, M. "Linking fatigue response of asphalt binders, mastics, and asphalt concrete mixture modified by nano-silica and synthesized polyurethane", International Journal of Damage Mechanics, 30(1), pp. 103-122, 2021. https://doi.org/10.1177/1056789520950766

[19] Saltan, M., Terzi, S., Karahancer, S. "Examination of hot mix asphalt and binder performance modified with nano silica", Construction and Building Materials, 156, pp. 976-984, 2017. https://doi.org/10.1016/j.conbuildmat.2017.09.069

[20] Rezaei, S., Ziari, H., Nowbakht, S. "Low temperature functional analysis of bitumen modified with composite of nano-SiO2 and styrene butadiene styrene polymer", Petroleum Science and Technology, 34(5), pp. 415-421, 2016. https://doi.org/10.1080/10916466.2016.1143841

[21] Rezaei, S., Khordehbinan, M., Fakhrefatemi, S.-M.-R., Ghanbari, S., Ghanbari, M. "The effect of nano-SiO2 and the styrene butadiene styrene polymer on the high-temperature performance of hot mix asphalt", Petroleum Science and Technology, 35(6), pp. 553-560, 2017. https://doi.org/10.1080/10916466.2016.1270301

[22] Sadiq Bhat, F., Shafi Mir, M. "A study investigating the influence of nano Al2O3 on the performance of SBS modified asphalt binder", Construction and Building Materials, 271, Article number: 121499, 2021.

https://doi.org/10.1016/j.conbuildmat.2020.121499

[23] Han, L., Zheng, M., Li, J., Li, Y., Zhu, Y., Ma, Q. "Effect of nano silica and pretreated rubber on the properties of terminal blend crumb rubber modified asphalt", Construction and Building Materials, 157, pp. 277-291, 2017.

https://doi.org/10.1016/j.conbuildmat.2017.08.187

[24] Duan, H., Zhu, C., Li, Y., Zhang, H., Zhang, S., Xiao, F., Amirkhanian, S. "Effect of crumb rubber percentages and bitumen sources on high-temperature rheological properties of less smell crumb rubber modified bitumen", Construction and Building Materials, 277, Article number: 122248, 2021. https://doi.org/10.1016/j.conbuildmat.2021.122248

[25] Chen, Z., Zhang, H., Liu, X., Duan, H. "A novel method for determining the time-temperature superposition relationship of SBS modified bitumen: Effects of bitumen source, modifier type and aging", Construction and Building Materials, 280, Article number: 122549, 2021.

https://doi.org/10.1016/j.conbuildmat.2021.122549

[26] Wang, D., Liu, Q., Yang, Q., Tovar, C., Tan, Y., Oeser, M. "Thermal oxidative and ultraviolet ageing behaviour of nano-montmorillonite modified bitumen", Road Materials and Pavement Design, 22(1), pp. 121-139, 2021.

https://doi.org/10.1080/14680629.2019.1619619
[27] Mohamed Jaafar, Z. F., Ramadhansyah, P. J., Masri, K. A., Mashros, N., Mohd Warid, M. N., Norhidayah, A. H., Yaacob, H. "The effects of nano kaolin clay modified bitumen on the softening point and storage stability", IOP Conference Series: Earth and Environmental Science, 682(1), Article number: 012062, 2021.

https://doi.org/10.1088/1755-1315/682/1/012062

[28] American Association of State and Highway Transportation Officials "AASHTO T53-09 Method of Test for Softening Point of Bitumen (Ringand-Ball Apparatus)", AASHTO, Washinton DC, USA, 2004.

[29] American Association of State and Highway Transportation Officials "AASHTO T316 Standard Method of Test for Viscosity Determination of Asphalt Binder Using Rotational Viscometer", AASHTO, Washington DC, USA, 2010.

[30] American Association of State and Highway Transportation Officials "AASHTO T313 Standard Method of Test for Determining the Flexural Creep Stiffness of Asphalt Binder Using the Bending Beam Rheometer (BBR)", AASHTO, Washington DC, USA, 2012.

[31] Liu, S., Cao, W., Fang, J., Shang, S. "Variance analysis and performance evaluation of different crumb rubber modified (CRM) asphalt", Construction and Building Materials, 23(7), pp. 27012708, 2009.

https://doi.org/10.1016/j.conbuildmat.2008.12.009

[32] TA Instruments "Rheology Applications Note Application of TimeTemperature Superposition Principles to Rheology", TA Instruments, New Castle, DE, USA, RN-11B, 1995

[33] Qin, Q., Farrar, M., Turner, T. F., Planche, J.-P. "Characterization of the Effects of Wax (Sasobit ${ }^{\circledR}$ ) on Asphalt Binder Fundamental Properties of Asphalts and Modified Asphalts III Product: FP 13", Western Research Institute, Laramie, WY, USA, 2015

[34] Kök, B. V., Aydoğmuş, E., Yilmaz, M., Akpolat, M. "Investigation on the properties of new palm-oil-based polyurethane modified bitumen", Construction and Building Materials, 289, Article number: 123152, 2021.

https://doi.org/10.1016/j.conbuildmat.2021.123152

[35] Monteiro, M. S. de S. de B., Cucinelli Neto, R. P., Santos, I. C. S., Silva, E. O. da, Tavares, M. I. B. "Inorganic-organic hybrids based on poly ( $\varepsilon$-Caprolactone) and silica oxide and characterization by relaxometry applying low-field NMR", Materials Research, 15(6), pp. 825-832, 2012. https://doi.org/10.1590/S1516-14392012005000121

[36] Lushinga, N., Cao, L., Dong, Z., Assogba, C. O. "Improving Storage Stability and Physicochemical Performance of Styrene-ButadieneStyrene Asphalt Binder Modified with Nanosilica", Sustainability, 12(21), Article number: 8968, 2020. https://doi.org/10.3390/su12218968

[37] Tang, Y. "Inhibition of Low-Temperature Oxidation of Bituminous Coal Using a Novel Phase-Transition Aerosol", Energy Fuels, 30(11), pp. 9303-9309, 2016. https://doi.org/10.1021/acs.energyfuels.6b02040

[38] Fauser, P., Tjell, J. C., Mosbaek, H., Pilegaard, K. "Quantification of Bitumen Particles in Aerosol and Soil Samples Using HP-GPC", Petroleum Science and Technology, 18(9-10), pp. 991-1007, 2000. https://doi.org/10.1080/10916460008949887 
[39] Jiménez del Barco Carrión, A., Subhy, A., Izquierdo Rodriguez, M. A., Lo Presti, D. "Optimisation of liquid rubber modified bitumen for road pavements and roofing applications", Construction and Building Materials, 249, Article number: 118630, 2020. https://doi.org/10.1016/j.conbuildmat.2020.118630

[40] Baskent Aydemir, E., Ozkul, M. H. "Investigation of effect of bitumen chemical composition, elastomeric polymer and paraffin wax additives on the properties of bitumen by using response surface method", Construction and Building Materials, 234, Article number: 117414, 2020. https://doi.org/10.1016/j.conbuildmat.2019.117414

[41] Memon, A. M., Hartadi Sutanto, M., Napiah, M., Khan, M. I., Rafiq, W. "Modeling and optimization of mixing conditions for petroleum sludge modified bitumen using response surface methodology", Construction and Building Materials, 264, Article number: 120701, 2020. https://doi.org/10.1016/j.conbuildmat.2020.120701

[42] Khairuddin, F. H., Yusoff, N. I. M., Badri, K., Koting, S., Choy, P. N., Misnon, N. A., Che Osmi, S. K. "Design and optimization of polyurethane modified bitumen (PUMB) using response surface method", IOP Conference Series: Earth and Environmental Science, 476, Article number: 012061, 2020.

https://doi.org/10.1088/1755-1315/476/1/012061
[43] Khairuddin, F. H., Alamawi, M. Y., Yusoff, N. I. M., Badri, K. H., Ceylan, H., Tawil, S. N. M. "Physicochemical and thermal analyses of polyurethane modified bitumen incorporated with Cecabase and Rediset: Optimization using response surface methodology", Fuel, 254, Article number: 115662, 2019. https://doi.org/10.1016/j.fuel.2019.115662

[44] Varanda, C., Portugal, I., Ribeiro, J., Silva, A. M. S., Silva, C. M. "Optimization of bitumen formulations using mixture design of experiments (MDOE)", Construction and Building Materials, 156, pp. 611-620, 2017. https://doi.org/10.1016/j.conbuildmat.2017.08.146

[45] Irfin, Z., Altway, A., Susianto, Suprapto, Anindita, Y. D. "Bitumen extraction from Asbuton using hot water process with $\mathrm{Na} 2 \mathrm{Co} 3$ as a sealing agent", Journal of Chemical Technology and Metallurgy, 54(4), pp. 770-777, 2019.

[46] Kar, S. S., Tiwari, D., Swamy, A. K., Jain, P. K. "Development of Response Surface Model for Mechanical Properties of Foamed Bitumen Mixtures", In: 71st RILEM Annual Week \& ICACMS 2017, Chennai, India, 2017, pp. 411-419. 